\title{
ARTE E RECONCILIAÇÃO EM HERBERT MARCUSE
}

Rafael Cordeiro SILVA ${ }^{1}$

- RESUMO: O artigo pretende explicitar a relação entre arte e reconciliação no pensamento de Herbert Marcuse, considerando-se vários de seus escritos que tocam no tema. Ao longo deles, percebe-se que o uso do termo reconciliação assume um duplo significado: por um lado, significa a possibilidade de que os temas sublimados da cultura possam ser efetivados no plano das relações materiais, o que implicaria o desaparecimento da arte; por outro, significa a imagem de um mundo harmonizado que a arte preserva em si e que se distancia da ordem social. Sob esse aspecto, a arte permanece utopia.

- PALAVRAS-CHAVE: Marcuse; Teoria Crítica; Escola de Frankfurt; filosofia social; estética.

Marcuse sempre foi visto, dentre os filósofos ligados ou influenciados pelo Instituto de Pesquisa Social de Frankfurt, como o menos resistente à teoria da identidade. Ainda que eles utilizassem a dialética negativa como método e criticassem igualmente Hegel pelo aspecto fechado e totalitário de seu sistema, não foram unânimes em aceitar o conceito de reconciliação como termo final para a teoria crítica da sociedade. Adorno mostra total incompatibilidade com este conceito hegeliano na obra Dialética negativa. Horkheimer, por sua vez, oscila entre a posição receptiva defendida em Eclipse da razão e o crescente distan-

1 Professor do Departamento de Filosofia da Universidade Federal de Uberlândia - UFU. rcsilva@ufu.br 
ciamento expresso em seus escritos posteriores. Mas o que dizer a respeito de Marcuse? Habermas sustenta que ele foi o mais afirmativo dentre os que se valeram do pensamento negativo. ${ }^{2}$ Ainda que tivesse sido menos resistente à perspectiva da reconciliação, como declara Martin Jay em A imaginação dialética (1977, p.80), que relação ela estabelece com a arte? Como hipótese de fundo, sustento que, embora presente, o conceito de reconciliação não pode ser tomado em um único sentido, quando referido às obras de arte e à crítica da cultura. Sob esse aspecto, tentarei mostrar como essa relação é tematizada ao longo dos escritos do autor. ${ }^{3}$

No ensaio "Sobre o caráter afirmativo da cultura", publicado em 1937, Marcuse reconstrói o percurso histórico que resultou na separação contemporânea entre cultura e civilização e fez com que ambas persistissem como âmbitos aparentemente opostos. Analisando o pensamento filosófico desde a Grécia até os expoentes da filosofia moderna, o filósofo mostra como a separação inicial entre teoria e práxis, caraterística da filosofia antiga, relaciona-se com a noção contemporânea segundo a qual a superestrutura aparece como desvinculada da infra-estrutura. As filosofias de Platão e Aristóteles fundamentam a separação entre a esfera do útil e necessário, de um lado, e a do belo e da fruição, de outro. A primeira corresponde aos esforços práticos que visam à conservação da vida e não pode ser erigida em objeto do conhecimento, pois é insegura e inconstante; a segunda relaciona-se ao âmbito do belo e da fruição e não pertence à esfera das coisas úteis e necessárias, o que faz com que sua apreensão seja possível unicamente por meio da "teoria pura". Dessa forma, a beleza e a felicidade, por serem aspectos

2 Em "Termidor psíquico e renascimento de uma subjetividade rebelde", Habermas assim descreve Marcuse: "Certamente, Marcuse não foi um pensador afirmativo e, todavia, foi o mais afirmativo de todos aqueles que defenderam a negatividade. Nele, o pensamento negativo manteve a força dialética da negação determinada e da abertura de alternativas positivas." Cf. Habermas, 1986b, p.284. Da mesma forma, Kellner (1998, p.XII) destaca as diferenças entre Marcuse e os demais componentes do Instituto de Pesquisa Social, ao afirmar que "em seu trabalho resolutamente utópico, Marcuse articula a visão da emancipação humana que distingue sua versão da Teoria Crítica. Enquanto Adorno, Horkheimer e outros membros do Instituto foram relutantes em desenvolver detalhadamente quaisquer conceitos ou esboços de uma sociedade alternativa, Marcuse tentou delinear alternativas utópicas para o modo de vida presente."

3 A investigação tem início em 1937, com o ensaio "Sobre o caráter afirmativo da cultura" e não com a tese de doutorado "O romance de arte alemão", defendida em 1922. Tal escolha se deve ao fato de que o ensaio de 1937 surgiu num momento em que Marcuse já estava identificado com os rumos teóricos da Teoria Crítica e com o projeto do Instituto de Pesquisa Social de Frankfurt. Ainda que fosse possível resgatar a relação entre arte e reconciliação em seus escritos anteriores, é no contato com os membros do Instituto que este conceito ganha vigor. 
que transcendem o âmbito da vida material, só devem ser buscados depois da satisfação das necessidades vitais. A filosofia antiga sustenta, portanto, que o gozo da verdade, do bom e do belo é prerrogativa de uma elite. E o conhecimento delas é atribuição do filósofo, visto estar ele dispensado da atividade produtiva.

Para a filosofia grega, verdade, beleza, bondade e felicidade não são valores universais. Somente na época burguesa, quando eles deixam de ser a ocupação do filósofo, é que se forma a cultura propriamente dita e tem lugar a universalização dos valores. Seu pressuposto pode ser ilustrado pela seguinte máxima:

A verdade de um juízo filosófico, a bondade de uma ação moral, a beleza de uma obra de arte devem, segundo sua essência, dirigir-se a todos, afetar a todos, comprometer a todos. Sem diferença de sexo e de origem, sem prejuízo de sua posição no processo de produção, os indivíduos têm de se submeter aos valores culturais... A "civilização" recebe alma da "cultura". (Marcuse, 1968, p.62)

Por continuarem persistindo - a cultura e a civilização - como dois campos separados na época burguesa, Marcuse afirma a prevalência de um tipo de compreensão da cultura que a eleva por sobre a base material. Essa situação é denominada cultura afirmativa e significa que os valores do bom, verdadeiro, justo e belo são válidos universalmente e realizáveis no "interior de cada sujeito", sem que esteja implícito o compromisso de transformar a realidade. Cada um, diante da cultura burguesa, pode ser atingido pela magnitude de seus valores, mesmo que persista a miséria material.

Essa forma de compreensão mantém estreita conexão com a práxis política. A cultura originada no período burguês traz a marca da divisão de classes entre dominadores e dominados, em que os encargos e os prazeres são repartidos injustamente. Porém, a cultura é endereçada a um sujeito abstrato, independentemente de sua posição de classe. Um exemplo desse traço afirmativo pode ser buscado na Revolução Francesa. A burguesia, interessada no colapso do Ancien Régime, sustentou como universalmente válidas a liberdade, a igualdade e a fraternidade, com o intuito de conseguir a adesão das camadas populares. Uma vez alçada ao poder e diante da reivindicação de liberdade, igualdade e fraternidade concretas, a burguesia responde com a cultura afirmativa: liberdade abstrata, igualdade abstrata e fraternidade abstrata. Todas as realizações da cultura evocam esses valores abstratos. Se para a construção da nova ordem eles possuíam caráter progressista, com a sua es- 
tabilização esses valores assumem uma função legitimadora do statu quo. "Aquelas forças que tiram proveito das piores relações sociais, servem-se agora de cada uma destas idéias para impedir a possível mudança que se faz necessária à humanidade" (Horkheimer, 1988, p.142). Assim evidencia-se o traço idealista que adquire a cultura na medida em que afirma apenas a universalidade interior dos valores: "à necessidade do indivíduo isolado ela responde com a humanidade universal; à miséria corporal, com a beleza da alma; à servidão exterior, com a liberdade interior; ao egoísmo brutal, com o reino virtuoso do dever" (Marcuse, 1968, p.66).

A cultura tomou a alma para si, instituindo-a como seu domínio próprio, já que a filosofia sempre se viu embaraçada em sua tentativa de abordá-la e preferiu discutir a razão como substância da individualidade, ao passo que a religião estabeleceu a grandeza da alma somente após a morte. Os valores da cultura são os valores da alma, do interior das pessoas e só alcançam o exterior a partir de dentro. Essa forma de compreensão caracteriza a cultura afirmativa: a exaltação do anímico é o seu mote. Para ela, o indivíduo se realiza como tal, não pelo uso da razão, mas pela alma que lhe confere a essência particular e a sua individualidade própria.

No capitalismo liberal, a alma escapa à lógica do mercado e por isso permanece à margem do mundo do trabalho. O novo sistema econômico alcançou sua hegemonia, entre outros, devido à revolução industrial, que foi possibilitada pela razão técnica, e necessitou apenas dos corpos, ou seja, da mão-de-obra, inicialmente para a manufatura e depois para a indústria mecanizada. A reificação corporal de homens, mulheres e crianças, condenados à exploração, miséria, penúria e sofrimento nas frentes de trabalho, é compensada pela exaltação da beleza da alma. Porém, a cultura afirmativa não se destina ao proletariado rude, mas à burguesia refinada que, graças à fruição estética, engrandece sua alma e se vê dispensada de refletir que a condição abastada na qual vive só é possível pela miséria dos trabalhadores.

A cultura anímica, quando usada para afirmar a realidade e ocultar a desigualdade, é ideologia. Entretanto, Marcuse enxerga nela outra função: consiste, ao mesmo tempo, em um protesto contra a situação vigente. Ao mostrar imagens belas, a cultura apresenta o mundo como possibilidade de ser diferente. E, em um contexto econômico marcado pela desigualdade social, a reivindicação de felicidade depõe contra a ordem estabelecida. Nisto reside o perigo dos próprios temas da arte 
burguesa. Ocultar e desvelar, afirmar e contestar - estes pares dialéticos caracterizam a essência da cultura.

Ao protestar contra a ordem vigente e reivindicar uma outra forma de existência, a obra de arte antecipa uma maneira nova de organização da humanidade, mais feliz, livre e racional. ${ }^{4}$ Mas, diante da impossibilidade de efetivação dessa nova realidade, a cultura conserva em seus temas a esperança de que o futuro possa ser melhor. Então, valendo-se da expressão de Stendhal, Marcuse afirma que a arte é uma "promessa de felicidade" e, como promessa, reconcilia-se com a existência deplorável em que vive a maioria dos homens.

Em 1937, Marcuse pretendeu denunciar a falsa autonomia da cultura que, se for evocada como âmbito desligado das relações materiais que a engendram, contribui para afirmar e reforçar a miséria da realidade concreta. Ao se considerar que essa é a tônica que prevalece no ensaio, a reconciliação prometida no âmbito da obra indica que nada mudará e arte será sempre o outro lado da vida, distanciada das ações que os homens estabelecem entre si. Sob esse aspecto, a reconciliação faz parte do caráter afirmativo da cultura, enquanto apazigua o conflito.

Por outro lado, a promessa de felicidade e a reconciliação podem ser compreendidas sob um prisma diferente. Se há uma promessa de felicidade, isso significa que a beleza da arte poderá ser concretizada algum dia. As belas formas são uma antevisão da sociedade vindoura, mais racional e feliz e reconciliar significa nesse contexto transformar a arte em vida. Na verdade, é como se existissem dois mundos antagônicos - o real e o ideal - e o desejo de fazer com que o ideal se transforme no real condiz com este sentido de reconciliação. Na sociedade em que se efetivasse essa união, a arte perderia sua prerrogativa. Ao se eliminar a distância entre arte e sociedade, a arte, reconciliada com a vida, perderia sua função.

Em 1955, Marcuse publica Eros e civilização, obra que Wiggershaus considera a dialética do esclarecimento marcuseana ${ }^{5}$ e testemunho de sua maturação intelectual. Os capítulos 7 a 9 são dedicados à explicitação do papel da fantasia e da arte como forças de oposição ao princípio de realidade. Em termos gerais, o filósofo, baseado em Freud, adota a diferença entre princípio de realidade e princípio de prazer. $\mathrm{O}$

4 É interessante notar que o Marcuse dos anos trinta está mais próximo do Iluminismo ao associar a liberdade como uma tarefa da razão. Já o Marcuse maduro de Eros e civilização associa preferencialmente a liberdade à realização pulsional. Cf. também a nota 5 mais adiante.

5 Cf. a análise sobre Eros e civilização em WIGGERSHAUS, R. Die Frankfurter Schule, p. 553-565. 
primeiro corresponde à realidade estabelecida, à civilização propriamente dita, cujo processo de formação pressupôs a repressão da dinâmica pulsional para que a sociedade pudesse se manter.

Freud considera que o ser humano não pode ser feliz, já que a existência da sociedade depende da repressão pulsional. Dessa forma, caberia ao homem, portanto, se conformar à condição imposta pelo princípio de realidade, e para isto o processo terapêutico seria decisivo. Marcuse, ao contrário, pensa que o homem pode ser feliz e, para provar sua tese, amplia a terminologia freudiana, ao considerar uma diferenciação até então inexistente para o conceito de princípio de realidade. Este perde sua acepção estritamente biológica e passa a ser definido como princípio de desempenho, ou seja, uma forma histórica determinada - e portanto variável - do próprio princípio de realidade que Freud concebera como imutável. Além disso, com o conceito auxiliar de maisrepressão, Marcuse pretende designar toda forma adicional de repressão que é acrescida ao que ele chama de repressão básica, isto é, a quantidade mínima de repressão necessária para garantir a existência da sociedade.

O princípio de prazer diz respeito à dimensão erótica que transcende o aspecto da mera satisfação sexual. Corresponderia, na leitura de Marcuse, à plena satisfação pulsional tanto do indivíduo quanto da espécie. Típico das sociedades industrializadas é a absorção total do princípio de prazer pelo princípio de realidade, mediante sua repressão e utilização de suas energias para o aumento do desempenho produtivo. O projeto de uma nova sociedade se assentaria na constituição de um novo princípio de desempenho não-repressivo, e isto significaria dizer que toda repressão inútil - a mais repressão - que mutila e causa desprazer deveria ser abolida. Marcuse se refere em especial ao trabalho, a essa atividade alienada mas que, no entanto, é responsável pela produção de riqueza e pela supressão da miséria e necessidade. A riqueza hoje produzida permitiria dispensar as pessoas de longas jornadas laborais e o tempo restante poderia ser dedicado a formas possíveis de realização do prazer: o cultivo das faculdades mentais, o ócio criativo, dentre outras.

Todavia, as pulsões que permanecem em latência, ou seja, repressivamente sublimadas, manifestam-se em outras esferas paralelas à ordem do princípio de desempenho, como por exemplo a fantasia. Marcuse, ainda baseado em Freud, afirma que a fantasia é um processo cognitivo. Sob este aspecto, o processo mental está cindido; uma parte está mais ligada à razão e permanece voltada para o processo produti- 
vo, respondendo pelas castrações próprias da civilização, enquanto outra parte escapa do controle exercido pelo princípio de realidade.

Se a civilização fragmenta o indivíduo, a imaginação reivindica o indivíduo total, se a realidade caracteriza-se pela não liberdade, a fantasia nega a não liberdade. A fantasia ou imaginação encontra uma expressão no sonho, mas concretiza-se na arte, na literatura e nos mitos, que constituem meios pelos quais a linguagem do sonho ganha uma dimensão ao mesmo tempo objetiva e subjetiva. Neles vêm à tona tudo aquilo que o princípio de realidade reprimiu. Em Eros e civilização, Marcuse reafirma a mesma linha de pensamento desenvolvida em 1937. Insiste na possibilidade de manifestação de uma forma de existência oposta à realidade concreta. Assim, a imaginação evoca como valor de verdade tudo aquilo que se afigura como recusa do que é, ou como possibilidade do vir a ser. A arte é concebida como o veículo privilegiado de comunicação desta verdade reprimida, e a imaginação se volta para a reconciliação. Conforme o autor,

A imaginação vislumbra a reconciliação do indivíduo com o todo, do desejo com a realização, da felicidade com a razão. Conquanto esta harmonia tenha sido removida para a utopia pelo princípio de realidade estabelecido, a fantasia insiste em que ela deve e pode tornar-se real... (Marcuse, 1998, p.143. O itálico é meu)

Nesta passagem, dois aspectos são dignos de nota. O primeiro deles é o sentido da reconciliação, que deixo por ora em suspenso. O outro diz respeito à dissociação que o autor faz entre razão e felicidade. A razão está ligada ao princípio de realidade que, pela análise proposta em Eros e civilização, é a responsável pela repressão crescente e exclui, portanto, a imagem de felicidade. Esta permanece conservada na fantasia. No entanto, em 1937, quando da descrição de uma outra sociedade possível, expressa nos temas da cultura, Marcuse fez sempre referência ao seu caráter racional, livre e feliz. Em face da miséria reinante no mundo material, resultado da forma irracional de organização dos homens sob a égide da economia caótica que acarreta a infelicidade, a obra de arte apresenta uma sociedade racional e feliz. Os motivos dessa mudança de enfoque podem ser buscados na reavaliação, promovida pelos teóricos ligados ao Instituto, das condições de possibilidade de um projeto racional da sociedade. A razão, em seu sentido genérico, não é vista mais como condutora e porta-voz do processo de emancipação da espécie humana. Doravante, reconhecem que ela responde preferencialmen- 
te pela autoconservação da espécie, tendendo a tornar-se cada vez mais instrumentalizada. Marcuse, segundo me parece, partilha da análise de Horkheimer e Adorno, apresentada em Dialética do esclarecimento, embora tenha assumido a crítica da razão à sua própria maneira. ${ }^{6}$

O princípio de realidade separa razão e sentido, entendimento e sensibilidade. A dimensão estética pretende invalidar o princípio de realidade estabelecido e Kant apresenta a fundamentação dessa possibilidade. Na Crítica da faculdade de julgar estão presentes os argumentos que apontam para a reconciliação entre sensibilidade e entendimento por intermédio da imaginação. Marcuse apropria-se da reflexão kantiana com a intenção de mostrar que o campo da estética representa a imagem da superação do princípio de realidade. Daí segue-se que...

O esforço filosófico de mediação, na dimensão estética, entre sensibilidade e razão manifesta-se, pois, como a tentativa para reconciliar as duas esferas da existência humana que foram separadas por um princípio de realidade repressivo. A função mediadora é desempenhada pela faculdade estética... (Marcuse, 1998, p.179. O itálico é meu)

A arte, enquanto oposta ao princípio de desempenho, mantém sua vinculação com o princípio de prazer sublimado. Ela é capaz de colocar em suspenso a experiência repressiva que domina a espécie humana. Por isso, inspirado em Whitehead, Marcuse define a arte como a "Grande Recusa", ou seja, "o protesto contra a repressão desnecessária, a luta pela forma suprema de liberdade" (Marcuse, 1998, p.149).

A idéia de que a arte é o âmbito privilegiado da reconciliação suscita, uma vez mais, questões quanto a que o autor entende por este termo. Pelo número de vezes em que aparece, o sentido predominante deste conceito assemelha-se a um daqueles identificados no ensaio de 1937, a saber: a possibilidade de os valores da arte poderem ser realizados algum dia. A arte representa a vitória de Eros sobre Tânatos. Assim,

6 Conforme assinala Kellner (1984, pp.179-80), Marcuse concebe um novo conceito de razão, uma "razão libidinal" não repressiva dos sentidos. Em Eros e civilização encontra-se a seguinte passagem: "No grau em que a luta pela existência torna-se cooperação para o livre desenvolvimento e satisfação das necessidades individuais, a razão repressiva dá lugar a uma nova racionalidade da gratificação na qual razão e felicidade convergem" (Marcuse, 1998, p. 224). Então, se por um lado Marcuse assumiu a crítica de Adorno e Horkheimer à razão instrumental, por outro, ultrapassou-a e deu a ela um novo itinerário, cuja fundamentação passa pela teoria pulsional de Freud e pela junção de razão e sensibilidade proposta por Schiller. Este teria, segundo Marcuse, superado, em suas Cartas sobre a educação estética do homem, a concepção dualista de Kant, que separa razão e sensibilidade. 
o sentido visado é o "de uma reconciliação entre o princípio de prazer e o princípio de realidade" (Marcuse, 1998, p.193). Significa, portanto, a possibilidade de que a espécie venha a instituir novas maneiras de organização social, em cujo seio desapareça a repressão e o homem não seja mais o agressor, tanto de seu semelhante quanto da natureza. Mas é importante notar que esse conceito não significa o elogio da abundância como o oposto de escassez. Marcuse não sustenta uma fé inabalável no progresso técnico e tem claro que a abundância tende muito mais para o desperdício. Dessa forma, o que o autor pretende com o conceito central de reconciliação pode ser ilustrado com suas próprias palavras:

A reconciliação entre o princípio de prazer e o de realidade não depende da existência da abundância para todos. A única questão pertinente é se um estado de civilização pode ser razoavelmente concebido, no qual as necessidades humanas sejam cumpridas de modo tal e em tal medida que a mais-repressão possa ser eliminada. (Marcuse, 1998, p.151)

A partir do exposto sobre a relação de arte e reconciliação, razão e felicidade, em Eros e civilização, sustento uma proximidade do pensamento de Marcuse com o de Horkheimer. Este, de igual modo, defendeu, nos escritos da primeira metade dos anos 30, o projeto de uma teoria materialista em que razão e felicidade apareceram conjugadas. Essa posição, herdeira do Iluminismo, está presente também no Marcuse de 1937. Porém, em Eros e civilização, Marcuse não sustenta mais que razão e felicidade constituam um par conceitual que deva ser oposto à irracionalidade e infelicidade. Da mesma forma, em Eclipse da razão, de 1947, Horkheimer não apresenta qualquer argumento decisivo que faça supor que ambos os conceitos constituam uma unidade; ao contrário, tenta mostrar que o conceito de razão, originado no Iluminismo, é mera racionalidade subjetiva (meio-fim) que não implica por si só qualquer vínculo com a plena realização da espécie humana. O conceito de razão subjetiva e instrumental é o equivalente de princípio de desempenho no jargão marcuseano.

Eros e civilização apresenta ainda um outro significado menos explorado para o termo reconciliação. Isso reforça a posição de que Marcuse é não apenas pouco preciso como às vezes ambíguo em suas considerações. Aqui o sentido evocado para a função da arte é o oposto daquele outro, do qual o livro referenciado tematiza à exaustão. A passagem é a seguinte:

Dentro dos limites da forma estética, a arte expressou, embora de um modo ambivalente, o retorno da imagem reprimida de libertação; a arte era opo- 
sição. No presente estágio, no período de mobilização total, até essa oposição sumamente ambivalente parece não ser mais viável. A arte somente sobrevive na medida em que se anula, na medida em que poupa a sua substância mediante a negação de sua forma tradicional e assim se negando à reconciliação; quer dizer, na medida em se torna surrealista e atonal. Caso contrário, a arte contemporânea partilha do destino de toda comunicação humana autêntica: extingue-se. (Marcuse, 1998, p.145. O itálico é meu)

Aqui, Marcuse se aproxima da posição de Adorno. Chega inclusive a remeter o leitor a uma nota de rodapé referente à Filosofia da nova música. Mesmo não se podendo considerar Adorno um simpatizante do surrealismo, a inegável inclinação pela atonalidade fez deste filósofo, ao contrário de Horkheimer, um defensor da não-reconciliação. Marcuse reúne na mesma frase dois movimentos da arte contemporânea que pretenderam solapar as bases da forma estética tradicional, cujo traço reconciliatório é criticado. Além disso, ele chama a atenção, especialmente em referência ao surrealismo, para a necessidade de converter a arte em realidade, contra o aspecto embotado da arte burguesa. Pois bem, numa sociedade que tende a incorporar tudo e imobilizar qualquer força de oposição, a arte tradicional segue o mesmo destino. Por isso, a insistência nessas novas formas estéticas que se negam à reconciliação com a ordem vigente.

Em 1964, Marcuse publica O homem unidimensional e retoma algumas considerações sobre a relação entre arte e reconciliação. O contexto político-social que dá origem ao livro é marcado pela separação do mundo em dois grandes blocos - o comunista e o capitalista - e pela política intervencionista dos Estados Unidos. A guerra fria aumenta consideravelmente o perigo de que o mundo venha a se autoliquidar. Tal situação leva o autor a denominar a nação norte-americana de Estado Beligerante.

A ideologia da sociedade industrial utiliza-se da contínua ameaça de perigo como forma de perpetuar a dominação. Nessa época ocorre a expansão significativa dos artefatos de guerra, não apenas em quantidade, mas também em poder de destruição. O Estado Beligerante torna-se a própria imagem da racionalidade instrumental que, todavia, não se materializa apenas na indústria bélica: a ideologia da dominação legitima-se também pelo incremento das políticas públicas de bem-estar social, associadas ao crescente poder de compra dos trabalhadores norte-americanos. Marcuse deixa claro o caráter indecente e irracional de uma sociedade que faz do supérfluo e do desperdício o sinônimo de felicidade. Diante desse cenário, a crítica parece estar paralisada pelo poder de disposição da razão instrumental. 
As forças de oposição estão liquidadas, tamanho o poder de integração da sociedade industrial. O que caracterizava a sociedade prétecnológica era a necessidade de legitimação da ordem vigente por intermédio da ideologia. Esta significa tanto a ideologia da troca justa, que foi desmascarada por Marx, quanto a cultura afirmativa, que pressupunha um abismo com a realidade social. Real e ideal haviam de estar necessariamente separados e a esfera da cultura, desvinculada da base material, enquanto afirmava a beleza da alma, ratificava a miséria do corpo levada a cabo pela realidade material.

O que é novo hoje é o fato de que "a realidade ultrapassa sua cultura" (Marcuse, 1994, p.56). O encurtamento do antagonismo entre cultura e realidade caracteriza a sociedade unidimensional. Isso significa que a realidade tecnológica mostra-se tão poderosa que as suas conquistas resolvem os problemas existentes na sociedade pré-tecnológica, eliminando os contrastes com a cultura superior. Por isso, os elementos de oposição presentes na cultura são eliminados. A sociedade unidimensional é aquela que, em face das conquistas da ciência e da técnica, "realiza" a promessa de felicidade contida na cultura burguesa. Em contraste com esta sociedade existia uma cultura bidimensional caracterizada pela presença dos elementos culturais de oposição. Hoje, ocorre a assimilação destes elementos ideais, que são incorporados à realidade existente.

O problema não se resume ao fato de a cultura bidimensional ter sido substituída pela cultura de massa. Esta é apenas uma das conseqüências do capitalismo avançado. Sob este aspecto, Marcuse em nada diverge de Adorno e Horkheimer: a engrenagem social precisa da energia do trabalhador para continuar em funcionamento. Esta energia é reposta diariamente através de doses maciças de cultura produzida industrialmente. Adorno afirma, mais especificamente, que a cultura produzida para as massas funciona como se fosse um cimento social, ${ }^{7}$ Marcuse acrescenta a este raciocínio a idéia de que também os valores da cultura bidimensional "servem como instrumentos de coesão social" (Marcuse, 1994, p.57). ${ }^{8}$

7 Em "Sobre música popular", texto de 1941, Adorno diz textualmente: "Em grande parte, a música é, hoje, um cimento social" (Adorno, 1994, p.138).

8 É inegável a semelhança de Marcuse com Adorno, que já havia criticado, em textos anteriores, a transformação da cultura superior em mercadoria através da prevalência do valor de troca em relação ao valor de uso. Cf. "O fetichismo na música e a regressão da audição" de Adorno, publicado em 1937. 
O homem unidimensional, quando trata da cultura, denuncia também o fato de que a sociedade industrial realizou uma falsa reconciliação entre a civilização e a cultura. Se, em 1937 Marcuse se voltou contra o distanciamento da cultura em relação à base material que a produzira, em 1964 ele contesta a cooptação da cultura pela esfera da civilização. O capitalismo avançado pretende fazer valer a máxima de que a felicidade coincide com a realização material. Agora, depois da planificação econômica e segundo a ideologia em voga, todo trabalhador, que antes vivia em uma situação deplorável, é "feliz", pois pode ter acesso aos bens materiais, ter sua jornada de trabalho reduzida e desfrutar das "maravilhas" proporcionadas pelas conquistas tecnológicas. Aquela promessa de felicidade típica da arte burguesa concretiza-se equivocadamente na forma de mercadorias disponíveis para usufruto.

A denúncia da falsa reconciliação leva Marcuse a evocar o aspecto de uma certa alienação consciente em relação ao mundo dos negócios e da vida calculável e lucrativa, presente na cultura superior e irreconciliável com a ordem estabelecida. Se essa cultura é pré-tecnológica, visto que tem suas bases no capitalismo incipiente, é também pós-tecnológica, pois "suas imagens e posições mais avançadas parecem sobreviver à sua absorção dentro das comodidades e dos estímulos administrados; elas continuam a seduzir a consciência com a possibilidade de seu renascimento na consumação do progresso tecnológico" (Marcuse, 1994, p.59). Este é o aspecto irreconciliável que persiste, mesmo depois da falsa reconciliação.

Marcuse critica, portanto, o poder absorvente da sociedade que esgota e invalida o conteúdo antagônico da arte. Em Eros e civilização, o autor definira a arte burguesa como a Grande Recusa. Diante do poder avassalador da realidade tecnológica, seria oportuno dizer que a sociedade industrial recusa a Grande Recusa. Ou seja, os rumos do capitalismo avançado invalidam a essência da arte. A forma com que a cultura superior é retomada e difundida faz com que sua intenção primordial seja modificada. Mesmo a alienação da cultura superior, que se mostrava nas obras tanto afirmativas como negativas, é refuncionalizada nos termos de uma estética da dominação. "A dominação tem sua própria estética e a dominação democrática tem sua estética democrática" (Marcuse, 1994, p.65). O filósofo reconhece que essa tendência tem um caráter irreversível.

A estética da dominação tem um poder acaçapante: transforma em produtos palatáveis a Grande Recusa, as vanguardas e os beatniks. Convertidos em diversão, eles não colocam em perigo o funcionamento do 
sistema. Ambas, a cultura superior e a cultura de massa, fazem parte do pluralismo harmonizador que caracteriza a sociedade industrial. Assim, as grandes obras persistem, mas sobrevivem lado a lado com a cultura para as massas que, em contrapartida, apresenta formas de satisfação muito mais imediatas do que mediatas. A alienação artística sublimada, em princípio irreconciliável com a realidade, serve agora para distração e para os negócios. Isso significa que ela é dessublimada, mas trata-se de uma dessublimação repressiva, pois "estende a liberdade ao mesmo tempo em que intensifica a dominação" (Marcuse, 1994, p.72).

Marcuse, em $O$ homem unidimensional, arrola argumentos suficientes que deixam transparecer uma posição pessimista quanto ao potencial da arte nas sociedades contemporâneas. Mesmo reafirmando a dimensão de protesto da cultura superior e das vanguardas artísticas, prevalece a constatação de que as possibilidades de mudança políticosocial rumo a um novo homem e a uma nova sociedade estão estagnadas e a crítica, que seria o elemento propulsor para esta transformação, está paralisada.

Essa posição é colocada em suspenso três anos depois com o aparecimento de um opúsculo intitulado "A arte na sociedade unidimensional", de 1967. O contexto que dá origem à publicação desse artigo é marcado pela explosão dos movimentos de protesto. Marcuse, há muito tempo descrente da capacidade revolucionária do proletariado, ancora suas esperanças nos grupos alternativos que reivindicam ao mesmo tempo cidadania e democracia. Assim, ele não hesita em aderir à causa dos negros e estudantes. O apoio ao movimento Black Power e aos protestos estudantis contra a guerra do Vietnã, se por um lado elevaram o prestígio do pensador junto à Nova Esquerda, por outro, valeram-lhe a pecha de "asqueroso cão comunista", dada pelos segmentos conservadores organizados.

"A arte na sociedade unidimensional" volta a indagar sobre qual o papel da arte em um momento histórico em que tanto a linguagem tradicional como a linguagem elaborada se encontram petrificadas, mudas e incapazes de comunicar o que acontece. Nesse pequeno ensaio, o autor continua sustentando, como em outros escritos anteriores, o potencial liberador da arte. Mas agora diz explicitamente que a linguagem da arte é a única linguagem revolucionária que ainda resta. Mais ainda, a concepção de arte deixa de estar referenciada exclusivamente à cultura superior e às vanguardas artísticas. As canções de Bob Dylan são agora invocadas como exemplo de sobrevivência artística. Ao referir-se às manifestações dos estudantes, afirma: 
Quando assisti e participei de suas demonstrações contra a guerra do Vietnã, quando os ouvi cantar as canções de Bob Dylan, senti de algum modo, e isto é muito difícil de definir, que esta é, na verdade, a única linguagem revolucionária que hoje nos resta. (Marcuse, 1990, p.245)

Esse texto pode ser considerado de transição, pois ratifica posições anteriores e que ainda continuarão presentes nos últimos escritos do autor, como por exemplo toda a discussão sobre a dimensão cognitiva da arte. ${ }^{9} \mathrm{O}$ texto também introduz dúvidas quanto a alguns pontos de vista que mais tarde serão abandonados, como por exemplo a simpatia pelo surrealismo.

Marcuse mostra que, no contexto atual, a possibilidade da arte como arte é vazia de sentido e portadora de uma falsa neutralidade. Mais do que nunca, ela tem uma dimensão política, refletida na sua finalidade de ser a negação definitiva da realidade estabelecida e a realização imaginária de um modo possível de existência de homens e coisas para além do Establishment. Todavia, Marcuse ressalta que o universo estético é inalcançável: "a arte poderia realizar-se somente permanecendo ilusão e criando ilusões" (Marcuse, 1990, p.249).

A busca de novas linguagens sempre fez parte da expressão artística, de modo a cumprir objetivos revolucionários contra a ordem estabelecida. O surrealismo, antes descrito como exemplo de arte que não sucumbiu e que recusara a reconciliação, é visto agora como manifestação artística que se tornou mercadoria rentável. Sendo assim, deixou de cumprir as funções que justificaram seu aparecimento. O argumento do autor aponta para a efemeridade da linguagem da arte, que só dura até o momento em que preserva uma certa autonomia. Isso não acontece mais com o surrealismo e, não por acaso, Marcuse alude ao potencial revolucionário das canções de Bob Dylan. Vale igualmente, nos dias de hoje, a mesma observação sobre este compositor, pois já se tornou também mercadoria vendável. Alguns anos depois, em entrevista concedida a Habermas, Marcuse explica mais precisamente que deixou de encarar o surrealismo como linguagem artística revolucionária, visto que este foi totalmente subsumido pelo sistema e perdeu seu caráter dialético. Segundo o filósofo, "um dos esforços do capitalismo tardio é o de voltar a integrar a arte na vida ou o de reconciliar arte e vida, com o afã

9 A pertinência dessa posição evidencia-se quando se a compara, por exemplo, com a de Horkheimer, que nos seus escritos finais não atribuía mais qualquer valor cognitivo às obras de arte. Elas teriam sucumbido à lógica do mundo administrado. 
de acabar com a forma estética ou o de destruir as obras-primas." (Habermas, 1986a, p.265. O itálico é meu)

Marcuse mostra, em 1967, que as dimensões estética e política devem permanecer indissociáveis. Contra a tendência da arte pela arte, o autor sustenta a posição de que arte e sociedade não podem ser pensadas em separado, pois a dimensão estética faz parte da própria vida. No entanto, isso não significa afirmar a idéia de uma "arte política" que transforma a sociedade por si só. Não, pois cabe a ela apenas liberar a sensibilidade para a transformação. Como isso é possível? Marcuse enfatiza que a beleza é este medium, pois ela é "o meio sensorial de uma verdade outra e ainda não realizada, a saber, a harmonia entre o homem e a natureza, a matéria e o espírito, a liberdade e o prazer..." (Marcuse, 1990, p.256).

A citação anterior evoca uma imagem da reconciliação. Ela descreve, em termos filosóficos, o que deveria ser a arte em sua relação com a sociedade. Esta é a única passagem em que é feita uma referência à reconciliação. Marcuse parece mais preocupado com a questão da forma para realizar a reconciliação: novas formas estéticas, visto que a dinâmica do Establishment tem a incrível capacidade de assimilar todas. Aí está o poder revolucionário da arte que é uma espécie de "arquitetura de uma sociedade livre" e dura no exato tempo de sua efemeridade.

A situação presente da arte é, segundo meu parecer, muito claramente expressa na exigência, formulada por Thomas Mann, de que se refute a Nona Sinfonia. Deve-se refutar a Nona Sinfonia não apenas porque é errada e falsa (...), mas também porque ela existe e é verdadeira dentro de seus próprios limites, inserindo-se em nosso universo como justificação daquela "ilusão" que não é mais justificável. A recusa de uma obra de arte, contudo, seria uma outra obra de arte. (Marcuse, 1990, 256)

A investigação sobre a forma estética é realizada por Marcuse em Contra-revolução e revolta, de 1972. Aqui o autor discute a possibilidade de rejeição da forma estética tradicional, pois ela separa arte e sociedade. Contra a falsa reconciliação promovida pela arte burguesa, o autor apresenta a necessidade de uma Revolução Cultural, que significaria a superação do caráter afirmativo da cultura. Como anteriormente mostrado, a reconciliação na arte burguesa tende a se tornar afirmação da ordem vigente. Daí Marcuse questionar o caráter ilusório deste tipo de reconciliação.

De acordo com esse ponto de vista, o que é questionado é a reconciliação como valor que não se compromete com a transformação da so- 
ciedade, substituindo-a por uma espécie de compensação pela miséria existente. Na medida em que os temas culturais evocam a beleza das formas enquanto a realidade mostra-se o oposto, pode-se falar em uma dissociação entre arte e sociedade. Desse modo, a reconciliação consoladora apazigua, pela forma estética, o desejo por uma ordem não-repressiva. A forma é considerada uma espécie de "duplicação invertida" da realidade material, pois realiza o irrealizável, ou seja, o que não pode ser ainda tornado real e permanece no nível do ideal, do ilusório. Assim, a forma estética é a herança da arte burguesa.

Como já fizera anteriormente, Marcuse mostra uma vez mais que a forma estética burguesa possui um elemento antiburguês, que se expressa na maneira de uma "alienação consciente" em relação à ordem estabelecida. Sob o aspecto de protesto, esse elemento deve ser preservado, já que há nele um poder cognitivo e libertador.

É uma segunda alienação, em virtude da qual o artista dissocia-se metodicamente da sociedade alienada e cria o irreal, universo "ilusório" no qual a arte por si só tem e comunica sua verdade. Ao mesmo tempo, esta alienação relaciona arte e sociedade: preserva o conteúdo de classe e o torna transparente. Como "ideologia", a arte invalida a ideologia dominante. (Marcuse, 1972, p.97)

Marcuse reconhece o caráter dialético da forma estética, ou seja, o elemento burguês na obra, assim como sua dimensão antiburguesa. Ele pretende preservar, pela Revolução Cultural, esse elemento antiburguês, mas reconhece que a Revolução Cultural não consegue fixar uma base social. A arte contemporânea fracassou em abolir seu hiato com a vida: de um lado, a sociedade não realizou a promessa contida na arte burguesa, ao contrário, promoveu a falsa reconciliação; de outro, a arte contemporânea pretendeu ser revolucionária, mas seu intento desmorona, visto que sua intenção de se transformar em vida é apropriada pela ordem vigente.

No opúsculo "A arte na sociedade unidimensional", Marcuse começa a reverter sua antiga idéia de morte da arte em favor de uma postura de vanguarda permanente. Mesmo criticando o surrealismo, ele apostara na capacidade de renovação da forma estética contra as formas burguesas. Por isso alude às canções de Bob Dylan e ao novo que o serialismo de Stockhausen representa diante da música de Beethoven. No entanto, em Contra-revolução e revolta, o autor se mostra simpático à preservação das qualidades progressistas da arte burguesa e revê suas posições anteriores, ao ressaltar que tais qualidades não reconciliam 
com o mundo. Nisto ela preserva seu valor de verdade, o que a arte contemporânea não consegue fazer.

É esta segunda alienação que desaparece hoje nos esforços sistemáticos para reduzir, senão fechar, o hiato entre arte e realidade. O esforço está destinado ao fracasso. Certamente, existe rebelião no teatro de guerrilha, na poesia da "imprensa livre", no rock - mantém-se artística sem o poder de negação da arte. No grau em que faz parte do real, perde a transcendência que opõe a arte à ordem estabelecida - permanece imanente a esta ordem, unidimensional, e assim sucumbe a ela. (Marcuse, 1972, p.101)

Marcuse mostra, portanto, quão inofensiva se tornou esta arte que aspirou a algum tipo de Revolução Cultural. O desaparecimento da "segunda alienação" leva consigo a possibilidade de oposição à sociedade unidimensional. Todavia, a tensão entre arte e revolução não desaparece de seu pensamento. Mesmo que a Revolução Cultural tenha pretendido ser uma proposta de superação da forma estética burguesa, ela teve contra si o fato de ter sido usada em favor da própria sociedade que ela contestava. Por outro lado, se a arte não realizou a proposta do socialismo, mesmo assim ela persistirá, assimilando internamente na forma estética esta tensão com a revolução. Marcuse acredita que pela forma estética a arte preserva o momento de irreconciliabilidade. Mas isso não significa um aval ao retorno de qualquer forma tradicional. As formas se renovam à medida que caminha a humanidade, fracassando ou triunfando rumo a uma organização social melhor.

A dimensão estética, de 1977, refaz esse ponto de vista sobre a questão da forma. Ao criticar os princípios da estética marxista, radicaliza o conceito de forma, máxima expressão da autonomia da arte. Quando se acompanha a trajetória intelectual do autor, percebe-se que, nas últimas obras, ele se mostra mais aberto a esta postura sempre defendida por Adorno: a arte é absolutamente autônoma, contestando e transcendendo as relações sociais existentes. Assim, Marcuse revoga sua posição de 1967, em que, diante do contexto político, condenava a idéia da arte como arte. Agora, essa expressão passa a designar uma necessidade própria, intrínseca da arte. É parte inclusive do seu conteúdo revolucionário-político.

A forma estética de uma obra autêntica é definida como a maneira pela qual produz-se um afastamento de tudo aquilo que tem um conteúdo familiar, fazendo com que a arte se oponha à realidade e ao mesmo tempo esteja inserida no mundo. A obra de arte só tem sentido enquanto faz parte do existente. Ela deve estar inserida na sociedade, 
mesmo que não seja validada em função da classe social que a produziu, mas enquanto se opõe à realidade constituída. A arte transcende sua determinação social. Marcuse não invoca mais a necessidade de suplantar a forma estética tradicional em favor de uma nova. Esse argumento reforça a crítica à antiarte que já ocorria nos seus escritos no final dos anos sessenta e começo dos setenta: a antiarte sucumbe perante a realidade. Assim, para Marcuse, arte e vida devem persistir como dois domínios separados.

A arte é o testemunho da não-identidade. A negação de seu caráter conciliatório aproxima o pensamento de Marcuse aos de Adorno e Nietzsche. Na sociedade possível, ela persistirá sempre como o que é não-idêntico ao existente. Esse é mais um argumento que referenda a posição contrária à morte da arte. A realização da arte na vida, que consuma a reconciliação, parece ser uma idéia distante. Passada a euforia com a sociedade socialista e com os movimentos de protesto dos anos 60, ganha força a defesa de sua permanência.

Todavia, Marcuse reconhece ainda o duplo caráter da obra: ela é reconciliação e rebelião. Ambos os momentos coexistem. A reconciliação é entendida como a afirmação do existente enquanto o protesto anula esta tendência. Mesmo que a "solução" da obra seja a reconciliação, ela preserva o irreconciliável, pois será sempre o outro da realidade, resistindo em relação a ela.

A forma estética, em virtude da qual uma obra se opõe à realidade estabelecida é, ao mesmo tempo, uma forma de afirmação através da catarse reconciliadora. Esta catarse é um acontecimento mais ontológico do que psicológico. Baseia-se nas qualidades específicas da própria forma, na sua ordem não repressiva, no seu poder cognitivo, na sua imagem de sofrimento que chegou ao fim. Mas, a "solução", a reconciliação, que a catarse oferece, também preserva o irreconciliável. (Marcuse, 1986, p.65)

O percurso realizado tomou como referência textos significativos de todas as fases de Herbert Marcuse e mostrou que, quando o filósofo trabalha com o par conceitual arte e reconciliação, emergem pelo menos dois pontos de vistas mais gerais, porém distintos. Não apenas estes, mas eles aparecem como figuras mais fortes que têm desdobramentos, os quais tentei explicitar ao longo deste artigo. Estes dois aspectos principais podem ser resumidos da seguinte maneira:

1. Existe um sentido, que chamarei extrínseco, em que a arte é concebida como o pólo oposto da base material. Enquanto a realidade ca- 
racteriza-se pela maior repressão e ausência de liberdade, o universo da arte postula um mundo não-repressivo, onde prevalece a liberdade. A reconciliação significa, nesse contexto, a possibilidade de que os temas sublimados da cultura possam ser efetivados no plano das relações que os homens estabelecem entre si. Essa perspectiva apontaria para a morte da arte, pois a oposição entre arte e vida seria superada.

2. O segundo sentido, aqui denominado intrínseco, significa que a arte preserva em si a imagem de um mundo reconciliado, ou seja, formas de vida e de organização humanas em que os homens adotariam novas relações não repressivas com seus semelhantes e com a natureza. Pelo motivo das várias formas de organização social não terem sinalizado para esta possibilidade transcendente, e talvez não o façam, a arte persiste negando-se à reconciliação com a ordem social. Assim permanece a arte porque permanece a utopia.

Marcuse está, em seus últimos escritos, mais próximo dessa segunda posição, como pode-se depreender da seguinte passagem:

O horizonte da história ainda está aberto. Se a lembrança das coisas passadas se tornasse um motivo poderoso na luta pela mudança do mundo, a luta seria empreendida para uma revolução até aqui suprimida nas revoluções históricas anteriores. (Marcuse, 1986, p.79)

SILVA, R. C. Art and reconciliation in Herbert Marcuse's thought. Trans/Form/ Ação, (São Paulo), v.28(1), 2005, p.29-48.

- ABSTRACT: This paper aims to clarify the relation between art and reconciliation in Herbert Marcuse's thought, according to some of his writings concerning the subject. These works employ the term "reconciliation" with two meanings: it means the possibility of effectuating within material relations the sublimed cultural themes - and this would result in the disappearance of the art; on the other hand, it means the image of a harmonic world which art preserves in itself and that stays away from social order. Under this aspect, art remains utopia.

- KEYWORDS: Marcuse; Critical Theory; Frankfurt School; social philosophy; esthetic. 


\section{Referências bibliográficas}

ADORNO, Theodor. O fetichismo na música e a regressão da audição. In: Textos escolhidos: Benjamin; Habermas; Horkheimer; Adorno. 2. ed. Trad. Luiz João Baraúna. São Paulo: Abril Cultural, 1983, pp.165-191.

Sobre música popular. In: Adorno: sociologia. 2. ed. Trad. Flávio R. Kothe. São Paulo: Ática, 1994, pp.115-146.

HABERMAS, Jürgen. Diálogo con Herbert Marcuse. In: Perfiles filosóficopolíticos. Trad. Manuel Jimenez Redondo. Madri: Taurus, 1986a, pp.237283.

Termidor psíquico y renacimiento de una subjetividad rebelde. In: Perfiles filosófico-políticos. Trad. Manuel Jimenez Redondo. Madri: Taurus, 1986b, pp.283-296.

HORKHEIMER, Max. Materialismus und Moral. In: Gesalmmelte Schriften, v.3. Frankfurt: S. Fischer Verlag, 1988, pp.111-149.

JAY, Martin. L'imagination dialectique. Trad. E. E. Moreno e Alain Siquel. Paris: Gallimard, 1977.

KELLNER, Douglas. Herbert Marcuse and crisis of Marxism. Berkeley; Los Angeles: University of California Press, 1984.

Preface to 1998 edition. In: MARCUSE, Herbert. Eros and civilization. Londres: Routledge, 1998, pp.X-XIX.

MARCUSE, Herbert. Über den afirmativen Charakter der Kultur. In: MARCUSE, H. Kultur und Gesellschaft I. Frankfurt: Suhrkamp Verlag, 1968, pp.56101.

A arte na sociedade unidimensional. In: LIMA, Luís C. Teoria da cultura de massa. 4. ed. Rio de Janeiro: Paz e Terra, 1990, pp.245-256.

Art and revolution. In: Counter-revolution and revolte. Boston: Boston Beacon Press, 1972, pp.79-128.

A dimensão estética. Trad. Maria Elisabete Costa. Lisboa: Edições 70, 1986

Eros and civilization. Londres: Routledge, 1998.

One-dimensional man. 2nd. ed. Londres: Routledge, 1994.

WIGGERSHAUS, Rolf. Die Frankfurter Schule. Munique: Carl Hanser Verlag, 1986. 